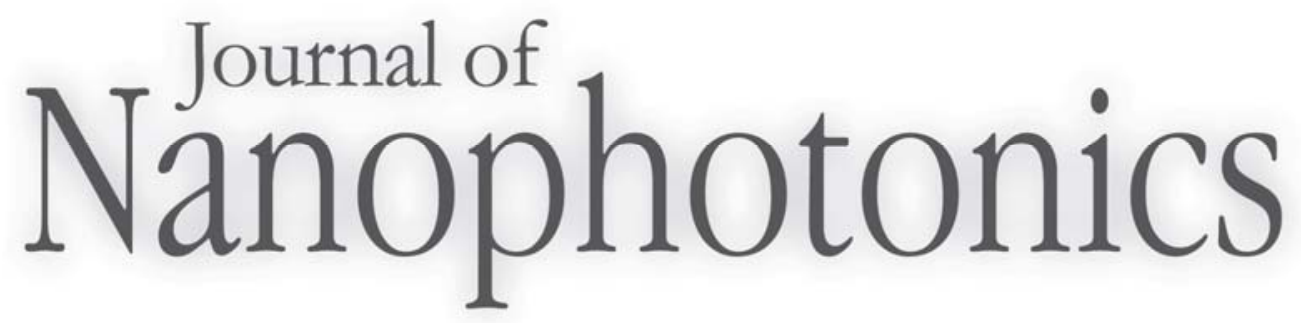

\title{
Guest Editorial: Selected Papers from the 2nd Mediterranean Conference on Nanophotonics
}

Zeev Zalevsky

Ekmel Ozbay

Ibrahim Abdulhalim

\section{O SPIE}




\title{
Guest Editorial: Selected Papers from the 2nd Mediterranean Conference on Nanophotonics
}

\author{
Zeev Zalevsky \\ Bar-Ilan University, School of Engineering, Ramat-Gan 52900, Israel \\ zalvesz@eng.biu.ac.il \\ Ekmel Ozbay \\ Bilkent University, Department of Physics, Department of Electrical and Electronics Engineering, \\ Nanotechnology Research Center - NANOTAM, Bilkent, Ankara 06800, Turkey \\ ozbay@bilkent.edu.tr \\ Ibrahim Abdulhalim \\ Ben-Gurion University, Electro-optics Engineering, Beer-Sheva 84105, Israel \\ abdulhlm@bgu.ac.il
}

The 2nd Mediterranean Conference on Nanophotonics (MediNano-2) was organized in Athens, Greece on 26-27 October 2009. A large variety of participants from more than 13 countries presented their work at the meeting. As in the previous MediNano meeting, the purpose was to promote collaboration within the field of nanophotonics among scientists, research facilities, and institutes from the Mediterranean countries and to establish a tradition of future nanophotonics conferences.

The manuscripts submitted for this special section focus on devices (metamaterial-, plasmon-mode-, and waveguides-based) as well as on nanophotonics-related measurement techniques such as differential evanescent light intensity imaging. 